\title{
HYPERMEDIA GLOSSES AS ADJUNCT AIDS TO READING: MALAYSIAN ESL LEARNERS'ATTITUDES
}

\author{
WAN ZULKIFLI WAN KASSIM
}

Centre for Fundamental and Continuing Education, Universiti Malaysia Terengganu, Malaysia

*Corresponding author: wanzul@umt.edu.my

Submitted final draft: 31 December 2020

Accepted: 18 January 2021

http://doi.org/10.46754/jbsd.2021.03.004

\begin{abstract}
Hypermedia glosses, in their role as adjunct aids to reading in computer-assisted language learning environment, have been studied quite extensively as to their effects on L2 learners' reading comprehension and incidental vocabulary learning. By contrast, these glosses have not been wellresearched as regards L2 learners' attitudes towards them. It is argued that learners' attitude towards instructional tools is an important variable because of its strong association with learners' success. Therefore, before investing time and financial resources into developing full-scale hypermedia glosses for use as instructional interventions, learners' attitudes towards the glosses need to be extensively investigated first. In light of this, the present study aimed to determine how hypermedia glosses are viewed by Malaysian ESL learners. The study employed descriptive research design, with data collected both quantitatively and qualitatively. Participants were a convenience sample of 40 low-intermediate ESL (English as a Second Language) undergraduates from a Malaysian public university in Kuala Nerus, Terengganu. They first read an electronic text containing 15 unfamiliar words for which hypermedia glosses were supplied through hyperlinks. These glosses displayed a combination of L1 (Malay) translations of the words and their corresponding images, either in static or animated format. After the reading activity, the participants gave their feedback by completing a brief questionnaire containing four items rated on a four-point Likert scale. Seven participants were later interviewed for additional insights. Based on the results, it was found that most of the participants viewed hypermedia glosses positively. Pedagogical implications will be discussed.
\end{abstract}

Keywords: Hypermedia, CALL, reading, ESL, attitude

\section{Introduction}

In $\mathrm{L} 2$ reading instruction, one of the adjunct aids to support learners is marginal glosses. These are brief notations that supply meanings of unfamiliar words in the forms of short definitions, L1 translations, or synonyms (Nation, 1983, 2001). In the reading texts, they are commonly placed either in the sides or in the bottom margins (Lomicka, 1998). Through the use of marginal glosses as adjunct aids, two of L2 reading-related issues have been dealt with. First, marginal glosses help prevent learners from incorrectly guessing the meanings of unfamiliar words in reading texts, especially ones that lack contextual clues (Haynes, 1993). Secondly, they reduce the reading interruptions caused by frequent pauses for a dictionary consultation (Crow, 1986; Bowles, 2004). Studies have shown that marginal glosses have helped L2 learners' reading comprehension and their incidental vocabulary learning to improve (Davis, 1989; Jacobs, Dufon \& Hong Cheng, 1994; Hulstijn, Hollander \& Greidanus, 1996; Watanabe, 1997; Mitari \& Aizawa, 1999; Tseng, Yeh \& Yang, 2015).

In computer-assisted language learning (CALL) environment, where reading materials are in electronic forms, marginal glosses take on a new life, with more options for their formats and designs. They have been referred to by a new name-hypermedia glosses - with a list of other variations including electronic 
glosses, multimedia glosses, online dictionary, computerized glosses, multimedia annotation, and electronic reading aids. Hypermedia glosses have been much discussed with regard to their advantages. First, hypermedia glosses appeal to learners because they are more interesting (Davis \& Lyman-Hager, 1997). They can take in not only text but images, animations, videos, even sounds (Yanguas, 2009); furthermore, these different media may be shown simultaneously in any combinations (Chun \& Plus, 1996b). Secondly, hypermedia glosses help maintain learners' level of concentration (Hong, 2010). The hypertext technology allows learners to quickly check on word meanings from within the text itself at a click of a mouse, thereby minimising reading interruptions. Thirdly, hypermedia glosses are not intrusive (Davis, 1989). They are normally designed to be initially hidden from view and will display only when requested by learners. Finally, and most importantly, in comparison to their traditional counterparts, hypermedia glosses are more effective. This was echoed by Evans, who remarked, "the integration of text, sound, and visual data clearly is of great benefit to the learners as this will reinforce comprehension, pronunciation, and contextual use in a way that traditional materials are not able to do" (1993, p.214).

The effects of hypermedia glosses on L2 learners' reading comprehension and incidental vocabulary learning have been extensively investigated. In some studies, hypermedia glosses were compared with marginal glosses (in printed texts), while in others, they were examined in terms of their various electronic formats and presentation (Chun \& Plass, 1996a, 1996b; Al Seghayer, 2001; Yoshii \& Flaitz, 2002; Cheng \& Good, 2009; Yanguas, 2009; Tabatabaei \& Shams, 2011; Turk \& Ercetin, 2014; Jung, 2016; Moradan, 2016; Sadeghi, Khezrlou \& Modirkhameneh, 2017). One of the more significant findings coming out of the studies has been that hypermedia glosses in dual forms of presentation (textual and pictorial) have been shown to be more effective (Tabatabaei \& Shams, 2011; Turk \& Ercetin, 2014; Moradan, 2016; Ramezanali, 2017). The effectiveness of the glosses that were presented in dual forms supported the Dual Coding Theory, which posits that when information is coded in both verbal and visual forms, it is easier to remember and recall (Paivio, 1991).

While there have been many studies that measured the effects of hypermedia glosses on L2 learners' reading comprehension and incidental vocabulary learning, by contrast, there have been few studies that investigated L2 learners' attitudes towards these adjunct aids. It is argued that learners' attitude towards instructional tools is very important. As the first argument, learners' attitude is highly related to learners' performance whether in traditional classrooms or in CALL, with positive attitude - towards the teacher, the language, the setting, and the input - and high motivation to learn the target language associated with successful learning (Warschauer, 1996). As the second argument, hypermedia glosses, for all their claimed positive effects on reading comprehension and vocabulary learning, are costly and time-consuming to prepare, especially for extensive reading purposes. Thus, before decisions are made regarding full-scale use of hypermedia glosses as adjunct aids to reading, learners' attitudes towards them need to be more extensively investigated first. If it is conclusively found that learners' attitudes towards hypermedia glosses are positive, and they are motivated to learn the target language through these adjunct aids, hypermedia glosses can be taken out of experimental laboratories and brought into application to be utilised by a larger number of learners, with higher likelihood of success. In addition, the cost and time spent on preparing these hypermedia glosses for use as instructional interventions will be justified (Lenders, 2008).

From the existing limited studies that investigated L2 learners' attitudes towards hypermedia glosses, several observations can be made. Generally, L2 learners have viewed positively the availability of hypermedia glosses in reading texts. They believed that the glosses have helped learned new words (Almutairi, 
2017; Alharbi, 2018; Ramezanali \& Faez, 2019). They agreed that glosses have been useful in that they provided them meanings of unknown words in the texts quickly, which has allowed them to improve their text comprehension (Ercetin, 2003; NaglaTaha Bashrie, 2017; Alharbi, 2018; Salimi \& Mirian, 2019). They also agreed that the use of hypermedia glosses to provide word meanings was "suitable" and "practical" (Lenders, 2008). They gave comments like "helpful", "time-saving", "easy", and "enjoyable" (Davis \& Lyman-Hager, 1997) and said that getting to discover new words with the help of glosses was "interesting" and “exciting" (Koren, 1999). Most L2 learners also believed that glosses have not interrupted their reading process (NaglaTaha Bashrie, 2017; Salimi \& Mirian, 2019). In addition, with regard to the formats and presentation of hypermedia glosses, learners also expressed their preferences. In Jacob, Dufon and Hong (1994), learners chose L2 definitions as their preference, provided that these were easy to understand (Jacob, Dufon \& Hong, 1994), while in a newer study (Kongtawee \& Sappapan, 2018), learners mentioned L1 as their choice. Learners in Ramezanali $(2017,2019)$ preferred videos/ animations in combination with translations, as did learners in Rezae and Shoar (2011) when asked about their choice between pictures and movie strips. L2 learners of various languages, namely Spanish, French, Russian, and English, have accorded hypermedia glosses positive views, and these learners were from various countries such as Saudi Arabia, Holland, Iran, Japan, Jordan, Korea, Taiwan, Turkey, and the United States of America (Roby, 1991; Davis \& Lyman-Hager, 1997; Koren, 1999; Gettys, Imhof, \& Kautz, 2001; Lenders, 2008).

The existing studies, although scarce, have provided useful insights. However, before conclusive generalisations can be made that L2 learners view hypermedia glosses favourably, more similar studies are needed so that the size of related literature can be further increased. It is to the best of the researcher's knowledge that no undergraduates from Malaysian universities have participated in studies of this nature. Hence, in an effort to fill the gap in the literature, the current study aimed to investigate Malaysian low-intermediate ESL (English as a Second Language) learners' attitudes towards the presence of hypermedia glosses in reading texts. The research questions were as follows:

1. Do the learners believe hypermedia glosses help them to remember the meanings of words?

2. Do the learners enjoy being able to look up word meanings quickly through hypermedia glosses without having to refer to a dictionary?

3. Do the learners believe hypermedia glosses disrupt their reading process?

4. Which formats of hypermedia glosses do the learners prefer?

The study used the descriptive research design. Data was collected both quantitatively and qualitatively. The quantitative data was obtained through a feedback questionnaire. The qualitative data was obtained from an interview with several participants.

\section{Materials and Methods}

\section{Participants}

The participants were 40 undergraduates who represented a convenience sample of a population of low-intermediate ESL learners at a Malaysian public university in Kuala Nerus, Terengganu. In the Malaysian University English Test (MUET) that awards Band 6 as the highest score, these students obtained either Band 1 or Band 2. At the time of the study, the participants were taking a required English remedial course and were already in two intact groups of 20 each. They were all Malays, comprising 37 females and 3 males aged between 19 and 20 . They agreed to participate in the study after being informed by their instructor that the session with them would be held during one of their regular classes.

\section{Electronic Reading Text}

The electronic reading text took the form of a diary entry written by a teenager. The content of 
the text revolved around the results day of the Malaysian Certificate of Education examination and what had happened to him then. The text was 489 words long and contained 15 words regarded by most low-intermediate ESL learners as unfamiliar. The 15 words were the following: sneak, sprint, crouch, descend, revive, furious, combustible, elated, stressed, anxious, brace, hatchet, burglar, colander, centipede. These words, coloured green for contrast, could be clicked to display their corresponding glosses. The glosses would appear underneath the clicked words in small popup windows over the text. Once the glosses were displayed, they could be hidden again by clicking on the words once more. Because of the difficulty in finding a suitable authentic passage that contained suitable words to be glossed, the text had to be composed from scratch by the researcher. The composing process was helped by the 13 words adapted from Sutton (1999). The result was the diary entry that included all the 13 words in different sentences. These 13 words (mentioned above) would become part of the 15 target words in the text, with the remaining two words (colander, centipede) selected and added later. The text was created in a Hypertext Markup Language (HTML) document. The target words were hyperlinked to electronic glosses using Javascript.

There were two versions of the electronic reading text. In both versions, the text was the same. The difference was the type of hypermedia glosses incorporated in each. In the first version, the glosses were in the forms of L1 (Malay) translations of the words and the static images that match the words (Figure 1). In the second version, the glosses contained L1 (Malay) translation and corresponding animated images (Figure 2). The L1 translations were obtained from a Malay-English dictionary. The static and animated images were obtained from the Internet.

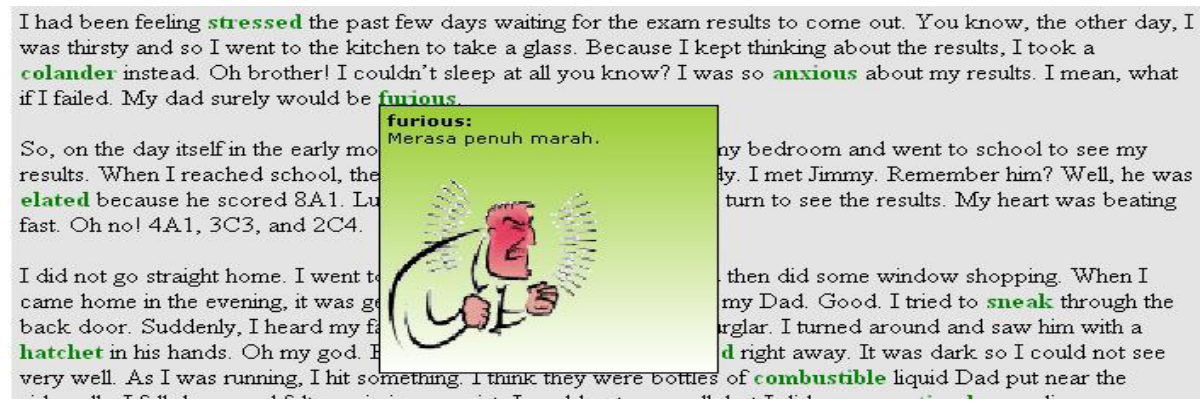

Figure 1: A hypermedia gloss showing a translation and a static image

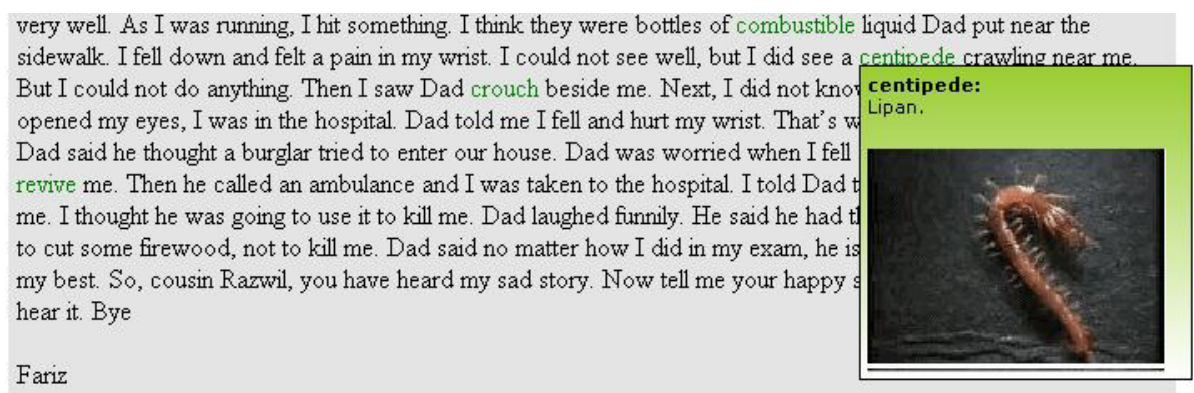

Figure 2: A hypermedia gloss showing a translation and an animated image

The decision to use L1 translations was made in view of the finding from a more recent study by Kongtawee and Sappapan (2018), in which learners chose L1 over L2 as their preference. It was also influenced by Schmitt's (2008) argument that the use of L1 is justifiable 
when it serves the purpose, that is, there is a positive transfer of L1 to L2 vocabulary learning. The decision to also display the images in combination with $\mathrm{L} 1$ translations was made to be in line with the findings that showed that hypermedia glosses presented in dual forms (textual and pictorial) were more effective than single form (Tabatabaei \& Shams, 2011; Turk \& Ercetin, 2014; Moradan, 2016; Ramezanali, 2017). In addition, the decision to include two formats of images - static and animatedwas made in view of learners' preference for animations (Rezae \& Shoar, 2011; Ramezanali, 2017).

To ensure the text could be understood by the participants and the target words were not already familiar to them, the text was first given to a few non-participants of similar level to be pilot tested. Based on the results from the pilot test, the text and the target words were accepted as appropriate. The text was uploaded to the server and could be accessed from a computer with an Internet connection.

\section{Feedback Questionnaire}

The self-developed feedback questionnaire contained four items that were formulated after considering those used in previous studies. These items measured the participants' attitude towards hypermedia glosses ("Hypermedia glosses helped me to remember the meaning of words."). For each item except the last, fourpoint Likert scale responses were provided for the participants to state their level of agreement (Strongly Agree, Agree, Disagree, Strongly Disagree). The last item, which asked the participants to state their preference for the type of images, provided the options Translation, Translation Plus Static Images, Translation Plus Animated Images. The items and the options were written in both English and Malay to ensure that the students fully understood them. The questionnaire was made available in hard copies.

Instead of the standard five-point Likert scale, a four-point version was used in the questionnaire, with midpoint option omitted
(Neutral/Neither Agree nor Disagree). This was done in conformity with Weijters, Cabooter and Schillewaert (2010), who argued, "offering a midpoint simply states that respondents with a truly neutral stance need to have the possibility of choosing the middle option and not be forced to choose a polar alternative by allowing respondents to indicate neutrality or ambivalence and thereby making people more comfortable when selecting a response option," (p.238).

\section{Procedure}

The study was conducted one week after participants had given their consent through their instructor. The two groups of participants were from two separate classes, so their independent learning session timetables differed. Therefore, the study involving each group was conducted on two different days to coincide with their sessions at the language laboratory.

\section{Group 1 (Malay Translation and Static-image Glosses)}

On the day of their independent learning session, the participants arrived at the language laboratory and sat in front of the computers. They were greeted by the researcher and then informed that they would be taking part in an evaluation of a new multimedia reading programme. Next, they were instructed to open a web browser on their computers and type a website address displayed in front on the projector screen to access the reading text. When the text appeared on their computer screens, they were shown how to display the glosses to obtain the meanings of unfamiliar words in the text. The glosses presented the word meanings through Malay translations and corresponding static images. When it was certain the participants knew what they had to do, they were instructed to begin reading. After the assigned time of 15 minutes, the participants were told to stop reading and close the multimedia reading programme. They were then handed the feedback questionnaire and completed it through self-administration. When the participants had finished, the questionnaires 
were collected, and the participants were thanked for their involvement in the study.

Immediately after the hypermedia gloss evaluation session, the group's instructor was requested to obtain volunteers from the group to participate in a follow-up interview. The interview session was held in one of the discussion rooms near the language laboratory during the group's next independent learning session. To record the interview, a video recorder was set up before the interview began. Three participants came to the interview. They were informed about the video recording, and they gave their verbal consent. During the interview, they were asked questions in Malay about their experiences with the hypermedia glosses and invited to give their opinions. As they were giving their opinions, also in Malay, the interview was being videotaped. The decision to use Malay was made to allow the participants to express themselves more freely and confidently. After the session had finished, they were thanked and allowed to leave.

\section{Group 2 (Malay Translation and Animated- image Glosses)}

Four days later, on the day of their independent learning session, the participants from Group 2 arrived at the language laboratory and sat in front of the computers. They were greeted by the researcher and were told that they would be evaluating a new multimedia reading programme. Next, they were instructed to open a web browser on their computers, followed by typing a website address displayed in front on the projector screen to access the reading text. When the text appeared on their computer screens, they were shown how to display the glosses to obtain the meanings of unfamiliar words in the text. The glosses presented the word meanings through Malay translations and corresponding animated images. When it was certain the participants knew what they had to do, they were instructed to begin reading. After the assigned time of 15 minutes, participants were told to stop reading and close the multimedia programme. They were then handed the feedback questionnaire and completed it through self-administration. When participants had finished, the questionnaires were collected, and they were thanked for their involvement in the study.

Immediately after the evaluation session, the groups' instructor was requested to obtain volunteers from the group to participate in a follow-up interview. The interview session was held during the group's next independent learning session, in one of the discussion rooms near the language laboratory. A video recorder was first set up before the interview took place to record the interview. Four participants came to the interview. The participants were informed about the video recording, and they gave their consent. During the interview, they were asked questions in Malay about their experiences with the hypermedia glosses and invited to give their opinions. As they were giving their opinions also in Malay, the interview was being videotaped. Malay was used to allow the participants to express themselves more freely and confidently. After the sessions had finished, they were thanked and allowed to leave.

\section{Analysis}

The analysis was conducted using Microsoft Excel Version 2010 for Microsoft 365 with Analysis Tool Pack Add-on installed. The questionnaire was tested for reliability and validity $($ Cronbach alpha $=.65)$. The responses for each item in the feedback questionnaire were analysed. The video-recorded interviews were transcribed, and the transcripts were translated into English. Appropriate responses from the transcripts were identified and to support the results from the feedback questionnaire.

\section{Results and Discussion}

\section{Demographic Details}

The demographic details of each group are as shown in Table 1 and Table 2. 
Table 1: Demographic details

(translation and static-image group)

\begin{tabular}{cccc}
\hline Item & Value & Frequency & Percentage \\
\hline Gender & Female & 18 & $90 \%$ \\
& Male & 2 & $10 \%$ \\
Age & 19 & 20 & $100 \%$ \\
MUET Score & Band 1 & 5 & $25 \%$ \\
& Band 2 & 15 & $75 \%$ \\
& Band 3 & 0 & $0 \%$ \\
& Band 4 & 0 & $0 \%$ \\
& Band 5 & 0 & $0 \%$ \\
& Band 6 & 0 & $0 \%$ \\
\hline
\end{tabular}

Table 2: Demographic details

(translation and animated-image group)

\begin{tabular}{cccc}
\hline Item & Value & Frequency & Percentage \\
\hline Gender & Female & 19 & $95 \%$ \\
\multirow{3}{*}{ Age } & Male & 1 & $5 \%$ \\
& 19 & 19 & $95 \%$ \\
MUET Score & 20 & 1 & $5 \%$ \\
& Band 1 & 4 & $20 \%$ \\
& Band 2 & 16 & $80 \%$ \\
& Band 3 & 0 & $0 \%$ \\
& Band 4 & 0 & $0 \%$ \\
& Band 5 & 0 & $0 \%$ \\
& Band 6 & 0 & $0 \%$ \\
\hline
\end{tabular}

\section{Perceived Effectiveness of Hypermedia} Glosses in Aiding Vocabulary Retention

Research question 1 asked, "Do the learners believe hypermedia glosses help them to remember the meanings of words?" To answer the research question, the participants' responses for Item 1 ("Hypermedia glosses help me remember the meaning of words.") in the feedback questionnaire were used.

\section{Group 1 (Translation and Static-image Glosses)}

The results for the first group showed that the percentage of participants who chose Strongly Agree was 55\%, while those choosing Agree was $45 \%$. The detailed results are shown in Table 3.

Table 3: Descriptive statistics (translation and static-image group)

\begin{tabular}{lcccccc}
\hline \multicolumn{1}{c}{ Item } & Strongly Disagree & Disagree & Agree & Strongly Agree & Mean & Std Dev \\
\hline $\begin{array}{l}\text { Hypermedia glosses } \\
\text { help me remember }\end{array}$ & $0(0 \%)$ & $0(0 \%)$ & $9(45 \%)$ & $11(55 \%)$ & 3.5 & 0.51 \\
the meaning of \\
words
\end{tabular}


The results from the feedback questionnaire were further explained by several responses from the participants in the interview. All the three participants generally agreed that the glosses helped them remember the meaning of the target words. When asked about the helpfulness of the multimedia glosses, Naim replied, "Yes, this feature really helped a lot." Ida added, "Some people have trouble understanding just words, so pictures help them to understand better." Dila was in favour of the multimedia glosses and reflected likewise when she said, "if the meaning is shown through picture, we will remember the words better." Naim commented:

I did not know what the words mean; then I used the program ... when I looked at the vocab [vocabulary][later], I instantly remember the pictures I saw and I can know the meaning of the words...If only translations are given, without image[s], maybe I can remember the words for three days. But if there are additional help in the form of images[s], I can remember longer. I can still remember until today.

\section{Group 2 (Translation and Animated-image Glosses)}

The results for the second group showed that the percentage of participants who chose Strongly Agree was $75 \%$, while those choosing Agree was $25 \%$. The detailed results are shown in Table 4.

Table 4: Descriptive statistics (translation and animated-image group)

\begin{tabular}{|c|c|c|c|c|c|c|}
\hline Item & Strongly Disagree & Disagree & Agree & Strongly Agree & Mean & Std Dev \\
\hline $\begin{array}{l}\text { Hypermedia glosses } \\
\text { help me remember the } \\
\text { meaning of words }\end{array}$ & $0(0 \%)$ & $0(0 \%)$ & $5(25 \%)$ & $15(75 \%)$ & 3.75 & 0.44 \\
\hline
\end{tabular}

The responses from the participants during the interview provided supports for the above results. All the four participants agreed on the usefulness of the glosses. Kimi, for example, remarked:

It has animation, so we will remember. Many of us like cartoons, right? So, when there is animation, even though we read it at the time, when we go home, we still remember. Like "witch", even during shower I still remember.

Radhi responded, "I saw the picture [animation], and then the translation 'ahli sihir' [a witch] further strengthened the memory [of the word]." Faridah added, "Sometimes when we see [read] translation[s], it is difficult to understand. Animation helps." When asked about how many words were still remembered after the treatment, Ida said, "My memory [of the words] ...was still strong." Kimi further commented, "Let's try and take a test today. I bet I will get all correct."

\section{Perceived Usefulness of Hypermedia Glosses in Providing Word Meanings}

Research question 2 asked, "Do the learners enjoy being able to look up word meanings quickly through hypermedia glosses without having to refer to a dictionary?" To answer the research question, responses for Item 2 ("Hypermedia glosses allow me to find word meanings quickly as opposed to using a dictionary") in the feedback questionnaire were used.

\section{Group 1 (Translation and Static-image Glosses)}

The results for the first group showed that $60 \%$ of the participants chose Strongly Agree and the other $40 \%$ chose Agree. The detailed results are shown in Table 5. 
Table 5: Descriptive statistics (translation and static-image group)

\begin{tabular}{lcccccc}
\hline \multicolumn{1}{c}{ Item } & Strongly Disagree & Disagree & Agree & Strongly Agree & Mean & Std Dev \\
\hline $\begin{array}{l}\text { Hypermedia glosses } \\
\text { allow me to find word }\end{array}$ & $0(0 \%)$ & $0(0 \%)$ & $8(40 \%)$ & $12(60 \%)$ & 3.6 & 0.50 \\
meanings quickly as & & & & & & \\
$\begin{array}{l}\text { opposed to using a } \\
\text { dictionary }\end{array}$ & & & & & & \\
\hline
\end{tabular}

The responses from the interview provided additional information to support the above results. All three participants expressed their satisfaction toward the provision of hypermedia glosses. Naim commented:

To me, the main problem when reading is vocab [vocabulary]. If we just read the text without any help, maybe it is difficult for us to understand the text. The words coloured green are not familiar words. If meanings are given plus pictures, makes it easier [to understand].
Dila responded, "If we read without aid, it is quite difficult to understand the story. Because there is help [the glosses], it becomes more interesting."

\section{Group 2 (Translation and Animated-image Glosses)}

The results for the second group showed $65 \%$ of the participants chose Strongly Agree. The detailed results are shown in Table 6.

Table 6: Descriptive statistics (translation and animated-image group)

\begin{tabular}{lcccccc}
\hline \multicolumn{1}{c}{ Item } & Strongly Disagree & Disagree & Agree & Strongly Agree & Mean & Std Dev \\
\hline $\begin{array}{l}\text { Hypermedia glosses } \\
\text { allow me to find word }\end{array}$ & $0(0 \%)$ & $0(0 \%)$ & 7 & $13(65 \%)$ & 3.65 & 0.49 \\
meanings quickly as & & & $(35 \%)$ & & & \\
$\begin{array}{l}\text { opposed to using a } \\
\text { dictionary }\end{array}$ & & & & & & \\
\hline
\end{tabular}

The responses from the interviews provide additional information to support the above results. The participants expressed satisfaction with the provision of hypermedia glosses. Ida replied, "This is a good program. When we read, we can know the meaning [through glosses], so we will comprehend the whole passage." Kimi claimed, "The thing [hypermedia glosses] is more effective. Because, it we just read like usual [without glosses], it becomes boring, right?" Radhi added, "I don't see the negative aspect, I see the positive aspect. This is a good combination [textual plus animated-image glosses]."

\section{Perceived Disruptiveness of Hypermedia Glosses}

Research question 3 asked, "Do the learners believe hypermedia glosses disrupt their reading process?" To answer the research question, responses for Item 3 ("Hypermedia glosses disrupt my reading process") in the feedback questionnaire were used.

\section{Group 1 (Translation and Static-image Glosses)}

The results for the first group showed that most participants $(85 \%)$ chose Disagree. The detailed results are shown in Table 7. 
Table 7: Descriptive statistics (translation and static-image group)

\begin{tabular}{lcccccc}
\hline \multicolumn{1}{c}{ Item } & Strongly Disagree & Disagree & Agree & Strongly Agree & Mean & Std Dev \\
\hline $\begin{array}{l}\text { Hypermedia glosses } \\
\text { allow me to find word }\end{array}$ & $0(0 \%)$ & $17(85 \%)$ & $2(10 \%)$ & $1(5 \%)$ & 2.2 & 0.52 \\
meanings quickly as & & & & & & \\
opposed to using a & & & & & & \\
dictionary & & & & & \\
\hline
\end{tabular}

During the interview, the participants said they did not think that the glosses were disruptive. Naim, for example, claimed, "I don't think the glosses were disruptive."

\section{Group 2 (Translation and Animated-image Group)}

The results for the second group showed that most participants $(75 \%)$ chose Disagree. The detailed results are shown in Table 8.

Table 8: Descriptive statistics (translation and animated-image group)

\begin{tabular}{|c|c|c|c|c|c|c|}
\hline Item & Strongly Disagree & Disagree & Agree & Strongly Agree & Mean & Std Dev \\
\hline $\begin{array}{l}\text { Hypermedia } \\
\text { glosses allow } \\
\text { me to find word } \\
\text { meanings quickly } \\
\text { as opposed to } \\
\text { using a dictionary }\end{array}$ & $0(0 \%)$ & $15(75 \%)$ & $2(10 \%)$ & $3(15 \%)$ & 2.4 & 0.75 \\
\hline
\end{tabular}

In the interview, all three participants said they did not think that the glosses were disruptive. Ida, for example, commented, "The glosses were not disruptive. Maybe we spent a bit longer looking at the animation, but I don't think they were disruptive."

\section{Learners' Preference for Hypermedia Glosses}

Research question 4 asked, "Which formats of hypermedia glosses do the learners prefer?"
To answer the research question, responses for Item 4 in the feedback questionnaire were used ("Which types of hypermedia glosses would you prefer?”).

\section{Group 1 (Translation and Static-image Glosses)}

The results for the first group showed that $65 \%$ of the participants chose Translation Plus Static Images option. The detailed results are shown in Table 9.

Table 9: Descriptive statistics (translation and animated-image group)

\begin{tabular}{lccc}
\hline \multicolumn{1}{c}{ Item } & $\begin{array}{c}\text { Translation } \\
\text { Only }\end{array}$ & $\begin{array}{c}\text { Translation and } \\
\text { Static Images }\end{array}$ & $\begin{array}{c}\text { Translation and } \\
\text { Animated Images }\end{array}$ \\
\hline $\begin{array}{l}\text { Which types of hypermedia glosses } \\
\text { would you prefer? }\end{array}$ & $1(5 \%)$ & $13(65 \%)$ & $6(30 \%)$ \\
\hline
\end{tabular}

The responses from the interview provided additional information to support the above results. Dila said, "I already like the one with static pictures."

\section{Group 2 (Translation and Animated-image Glosses)}

The results for the second group showed that all the participants $(100 \%)$ chose Translation Plus Animated Images option. The detailed results are shown in Table 10. 
Table 10: Descriptive statistics (translation and animated-image group)

\begin{tabular}{lccc}
\hline \multicolumn{1}{c}{ Item } & Translation Only & $\begin{array}{c}\text { Translation and } \\
\text { Static Images }\end{array}$ & $\begin{array}{c}\text { Translation and } \\
\text { Animated Images }\end{array}$ \\
\hline $\begin{array}{l}\text { Which types of hypermedia } \\
\text { glosses would you prefer? }\end{array}$ & $0(0 \%)$ & $0(0 \%)$ & $20(100 \%)$ \\
\hline
\end{tabular}

The responses from the interview with the participants provided additional information to support the above results. During the interview, all the participants expressed their liking of animation. Kimi, for example, claimed, "I like animation. The thing [animation] makes us remember. Just a text is boring." Radhi admitted, "When there is animation, we will understand more easily."

\section{Discussion}

The current study aimed to determine the attitudes of Malaysian ESL learners towards hypermedia glosses in their use as adjunct aids to reading in CALL. Overall, the results suggest that the learners have positive views towards the glosses. As expected, the results were congruent with those from earlier studies, where it was reported that learners generally had positive views towards hypermedia glosses, and they increased the learners' interest towards L2 reading.

All participants in both groups believed that hypermedia glosses helped them learn new words (Research Question 1). The results were similar to those in Almutairi (2018) and Ramezanali and Faez (2019). Almutairi (2018) conducted a study involving 41 students majoring in English at a university in Saudi Arabia to determine how they viewed the glosses provided in the reading texts. Based on the survey questionnaire results, the researcher concluded that majority of the students $(97.5 \%)$ believed the glosses helped them to improve their vocabulary. Ramezanali and Faez (2019) asked 132 students learning English at a private institute in Iran to read texts glossed with L2 definitions, audio, and video animations in multiple setups to investigate their attitude towards the glosses. Most students $(85 \%)$ reported that glosses helped them to remember the words. However, in the present study, there was a difference in the number of participants from each group who chose Strongly Agree. For the group with translations and static images as glosses, the percentage for Strongly Agree was $42 \%$; for the group with translations and animated images as glosses, the percentage was $82 \%$. The higher percentage in the latter group may be attributed to the animated images being more effective in the learners' views in aiding vocabulary retention. It may be argued that animated images increase learners' attention and made them focus more. The extra noticing then led to the words better remembered by the learners afterwards. The perceived effectiveness of animated images was illustrated through a response by a participant during the interview when he said he was able to remember the words long after this study was completed. Another participant also voiced out his confidence in remembering the words by "challenging" the researcher to test his retention of those words.

All participants in both groups agreed that hypermedia glosses allowed them to know word meanings quickly as opposed to using a dictionary (Research Question 2). The results were similar to those in earlier studies. Salimi and Mirian (2019) conducted a study involving 60 students at an Iranian language institute. After reading glossed texts for eight sessions, most students agreed that glosses were effective and that they saved time. NaglaTaha Bashrie (2017) aimed to determine how 62 Arabicspeaking students at a university in Sudan felt about using the glosses while reading online texts. The results indicated almost all students (94\%) agreed that glosses helped them to read faster as they did not need to stop reading for checking for the meanings in the dictionary. This agreement found in the present study may be related to the fact that the participants 
were already familiar with computer-assisted language learning. As part of their remedial English course requirements, the participants had to complete weekly independent learning sessions at the language laboratory using multimedia English learning software. By the time they participated in the study, they had completed ten weeks of independent learning sessions. A period of ten weeks is considered long enough for a person to be familiar with the nuances of technology. However, again, there was a difference in the number of participants from each group who chose Strongly Agree. For the group with translations and static images as glosses, the percentage for Strongly Agree was $53 \%$; for the group with translations and animated images as glosses, the percentage was $71 \%$. One possible explanation for the higher percentage of Strongly Agree choice for the latter group maybe the novelty factor. It is likely that when they encountered the animated images in the hypermedia glosses in the reading text, it was for the first time. Hence, the experience was an enjoyable one, leading more participants to express strong agreement with Item 2 in the feedback questionnaire. As one participant noted in the interview, most of them liked cartoons. When they saw animated images embedded into a reading text through hypermedia glosses, they automatically created a favourable impression of these glosses.

Most of the participants in both groups believed that the hypermedia glosses did not disrupt their reading process (Research Question 3). This is congruent with the result from NaglaTaha Bashrie (2017), which showed that $94 \%$ of the participants did not feel that glosses interrupted their reading. It is important to determine this as some earlier studies posit that glosses had a tendency to disrupt the reading flow and therefore reduced text comprehension (Mondria, 2003). In the present study, the number of participants choosing Strongly Agree was roughly the same, $79 \%$ for the first group and $76 \%$ for the second. However, some participants in both groups did find the glosses disruptive, with more participants (18\%) in the second group (translations and animated images) choosing Strongly Agree. The reasons why some participants found hypermedia glosses disruptive may be due to how they define the term disruptive and what type of readers they are. Some readers prefer to read texts continuously without any disruptions, even for quickly checking the meaning of certain unfamiliar words in the texts. The participants who labelled the glosses disruptive were most likely of this type. Those who did not think that the glosses were disruptive might have looked at the feature as something more beneficial. They believed that they should pause their reading and make full use of the glosses. In support of the hypermedia glosses not being a nuisance during reading, one participant said in the interview that the glosses were not disruptive and that spending a bit longer looking at the animated images might work in their favour instead, in the form of the words being better remembered.

When each group was asked which types of glosses they preferred (Research Question 4), all participants chose hypermedia glosses that contained translations and images; no participant chose to have only translations. This suggests that, images whether static or animated have their own appeal and can be utilised for the purpose of enhancing language learning. Further, when images are combined with textual information, such as translations, their effectiveness at aiding memory retention becomes greater, as posited by Paivio's Dual Coding Theory (1991). Between static and animated images, however, responses from the participants suggest that the latter have more appeal. For the first group (translations and static images), most of the participants chose to have static images (63\%). However, the other 37\% chose animated images. This suggests that even when they had not seen the animated images as used in the hypermedia glosses, the appeal of these images already won them over. As for the second group (translations and animated images), it was not a surprise that all participants chose Animated Images as their preference. During the experiment, they had the opportunity to utilise the hypermedia glosses containing the animated images (together with the translations) 
and discovered how more appealing and more effective they were.

There were some limitations in the current study that can be addressed in future studies. The first limitation was the scope of the study. The study only investigated low-intermediate ESL learners who obtained MUET 1 and 2. In future studies, the scope may be widened to include students with higher MUET scores so that comparison can made across different levels of English proficiency. The second limitation was the sample, which consisted of 40 lowintermediate Malaysian ESL undergraduates aged between 19 and 21. The characteristics of the sample limited the results' generalizability to the larger population comprising Malaysian ESL learners of varying ages and English competency levels. The size of the sample (40) was on the smaller side, again limiting the results' generalizability to the larger population. Future studies should include larger number of participants and participants of varying English competency levels. In addition, gender distribution in the sample was unequal, with the majority of the participants being female. This prevented an analysis of the difference between gender in terms of how they viewed the hypermedia glosses. The third limitation was the duration of the study. The participants read only one text for 15 minutes before they were asked for their opinions regarding hypermedia glosses. The time maybe too short to allow the participants to have the full experience using the feature. In future studies, the participants should be allowed to read more than one text, and if possible, the setting should be set up to replicate real-life extensive reading activity. The fourth limitation was the absence of data that showed whether participants did indeed access the hypermedia glosses and how long they spent on each gloss. Having this type of data could lend further validity to the results. In addition, it would provide information regarding the interactions between the reading, the glosses, and the learners. Future studies should be set up so that this data can be collected. Despite these limitations, the results obtained are valid for the purpose of answering the research questions asked in this study.

\section{Conclusion}

This study aimed to investigate the attitudes of low-intermediate Malaysian ESL learners towards hypermedia glosses in their role as adjunct aids to reading in CALL. Based on the results obtained from the feedback questionnaire and the interviews, it can be concluded that the learners have positive views towards the glosses. These hypermedia glosses have been shown in previous studies to improve reading comprehension and vocabulary learning. Owing to the effectiveness of these hypermedia glosses, it is important to find out the learners' attitudes towards these glosses, as positive attitudes will more likely lead the learners to use the technological feature. As researchers have been focusing on reading comprehension and vocabulary learning aspects of the hypermedia glosses, little attention has been paid to learners' attitudes. In this study, the learners had the opportunity to read an electronic text that was enhanced with hypermedia glosses containing L1 translations and static/animated images. Afterwards, they were asked about their opinions on the glosses through a feedback questionnaire and interviews. Their responses were used to answer the research questions. Based on the results of this study, practitioners should consider implementing extensive reading in CALL environment and incorporating hypermedia glosses for their students. Future studies might build from these results and conduct experiments to lend further validity and overcome the limitations. Lastly, this study has contributed to the existing literature by closing the knowledge gap in the research involving learners' attitude, through its investigation of these attitudes in the context of hypermedia glosses as adjunct aids to reading in CALL environment.

\section{Acknowledgements}

The author thanks Associate Professor Dr. Habsah Mohamad (Universiti Malaysia Terengganu) for useful discussions. 


\section{References}

Alharbi, B. (2018). The impact of glossed texts on reading comprehension among tertiary Saudi students. English Language Teaching, 11(3), 153. doi:10.5539/elt.v11n3p153

Almutairi, E. H. (2017). Incidental L2 vocabulary learning through using hypertext glosses. College of Languages and Translation, Al-Imam Muhammad Ibn Saud Islamic University, KSA (Master's Thesis). Retrieved from Arab World English Journal (ID Number: 210, September 2018, 1-78. DOI: https://dx.doi.org/10.24093/ awej/th. 210

Al-Seghayer, K. (2001). The effect of multimedia annotations modes on L2 vocabulary acquisition: A comparative study. Language Learning \& Technology, 5(1), 202-232. Retrieved February 19, 2005, from http://llt. msu.edu/vol5num1/alseghayer/default.html

Cheng, Y. H., \& Good, R. L. (2009). L1 glosses: Effects on EFL learners' reading comprehension and vocabulary retention. Reading in a Foreign Language, 21(2), 119-142. Retrieved July 1, 2020 from https://nflrc.hawaii.edu/rfl/October2009/ articles/cheng.pdf

Chun, D. M., \& Plass, J. L. (1996a). Effects of multimedia annotations on vocabulary acquisition. The Modern Language Journal, 80, 183-198.

Chun, D. M., \& Plass, J. L. (1996b). Facilitating reading comprehension with multimedia [Electronic version]. System, 24(4), 503519.

Crow, J. T. (1986). Receptive vocabulary acquisition for reading comprehension. The Modern Language Journal, 70(3), 242-250. https://doi.org/10.1111/j.1540-4781.1986. tb05271.x

Davis, J. N. (1989). Facilitating effects of marginal glosses on foreign language reading [Electronic version]. Modern Language Journal, 73(i), 41-48.
Davis, J., \& Lyman-Hager, M. A. (1997). Computers and L2 reading: Student performance, student attitudes. Foreign Language Annals, 30(1), 58-72.

Ercetin, G. (2003). Exploring ESL learners' use of hypermedia reading glosses. CALICO Journal, 20(2), 261-283. Retrieved July 4, 2020, from www.jstor.org/stable/24149499

Evans, M. (1993). Nicolas: Using HyperCard with intermediate level French learners [Electronic version]. System, 21(21), 213219.

Gettys, S., Imhof, L. A., \& Kautz, J. O. (2001). Computer-assisted reading: The effect of glossing format on comprehension and vocabulary retention. Foreign Language Annals, 34(2), 91-106.

Haynes, M. (1993). The patterns and perils of guessing in second language reading. In T. Huckin, M. Haynes \& J. Coady (Eds.), Second language reading and vocabulary learning (pp. 46-63). Norwood, NJ: Ablex.

Hong, X. (2010). Review of effects of glosses on incidental vocabulary learning and reading comprehension. Chinese Journal of Applied Linguistics, 33(1), 56-72.

Hulstijn, J. H., Hollander, M., \& Greidanus, T. (1996). Incidental vocabulary learning by advanced foreign language students: The influence of marginal glosses, dictionary use, and reoccurence of unknown words [Electronic version]. Modern Language Journal, 80(iii), 327-339.

Jacobs, G., Dufon, P., \& Hong Cheng, F. (1994). L1 and L2 vocabulary glosses in L2 reading passages: Their effectiveness for increasing comprehension and vocabulary knowledge [Electronic version]. Journal of Research in Reading, 17(1), 19-28.

Jung, J. (2015). Effects of glosses on learning of L2 grammar and vocabulary. Language Teaching Research, 19(2), 1-21. Retrieved online on 1 July 2020 from http://tr.sagepub.com/content/ early/2015/03/12/1362168815571151. abstract. 
Kongtawee, P., \& Sappapan, P. (2018). The effects of L1 and L2 hypertext glosses on reading comprehension and vocabulary retention among Thai Secondary School students. Arab World English Journal, 9(3), 367. https://doi.org/10.24093/awej/ vol9no3.24

Koren, S. (1999). Vocabulary instruction through hypertext: Are there advantages over conventional methods of teaching? TESL-EJ, 4(1), 1-15. Retrieved February 21, 2005, from http://www.kyoto-su.ac.jp/ information/tesl-ej/ej13/a2.html

Lenders, O. (2008) Electronic glossing - is it worth the effort? Computer Assisted Language Learning, 21(5), 457-481, DOI: $10.1080 / 09588220802447933$

Lomicka, L. L. (1998). "To gloss or not to gloss": An investigation of reading comprehension online. Language Learning \& Technology, 1(2), 41-50. Retrieved June 21, 2005, from http://lit.msu.edu/vol1num2/article2/ default.html

Mitari, Y., \& Aizawa, K. (1999). The effects of different types of glosses in vocabulary learning and reading comprehension. Annual Review of English Language Education in Japan, 10, 73-82.

Mondria, J. A. (2003). The effects of inferring, verifying, and memorizing on the retention of L2 word meanings: An experimental comparison of the meaning inferred method and the meaning-given method. Studies in Second Language Acquisition, 25(4), 473499.

Moradan, A. (2016). The effect of glosses on incidental vocabulary learning of Iranian EFL learners. International Journal of Applied Linguistics \& English Literature, 5(6), Retrieved from URL: http://dx.doi. org/10.7575/aiac.ijalel.v.5n.6p.34

NaglaTaha Bashrie, A. (2017). The effect of using L1 and L2 glosses on developing university students' vocabulary and reading comprehension / NaglaTahaBashrieAlnour;
Mahmoud Ali Ahmed.- Khartoum: Sudan University of Science and Technology, college of language, $157 \mathrm{p}$. : ill. ; $28 \mathrm{~cm}$ -- PhD. http://repository.sustech.edu/ handle/123456789/18761

Nation, I. S. P. (2001). Learning vocabulary in another language. New York: Cambridge University Press.

Nation, P. (1983). Teaching and learning vocabulary. Wellington: English Language Institute, Victoria University.

Paivio,A. (1991). Dual coding theory: Retrospect and current status. Canadian Journal of Psychology, 45, 255-287. Retrieved June 12, 2005, from Ingenta database.

Ramezanali, N., \& Faez, F. (2019). Vocabulary learning and retention through multimedia glossing. Language Learning \& Technology, 23(2), 105-124. https://doi. org/10125/44685

Ramezanali, N. (2017). Short and longterm vocabulary learning and retention through multimedia glossing: A mixed methods research (Thesis). Retrieved from https://ir.lib.uwo.ca/cgi/viewcontent. cgi? article $=6249 \&$ context $=$ etd

Rezaee, Abbas \& Shoar, Neda. (2011). Investigating the effect of using multiple sensory modes of glossing vocabulary items in a reading text with multimedia annotations. English Language Teaching, 4. 10.5539/elt.v4n2p25.

Roby, W. (1991). Glosses and dictionaries in paper and computer formats as adjunct aids to the reading of Spanish texts by university students [Unpublished doctoral dissertation]. University of Kansas. Retrieved December 21, 2005, from Proquest database.

Sadeghi, K., Khezrlou, S., \& Modirkhameneh, S. (2017). Calling Iranian learners of L2 English: Effect of gloss type on lexical retention and reading performance under different learning conditions. Journal of Research in Reading, 40(2), 66-86. 
Schmitt, N. (2008). Instructed second language vocabulary learning. Language Teaching Research, 12(3), 329-363.

Sutton, J. W. (1999). A comparison of image and textual annotations of vocabulary items in multimedia-based reading passages and their respective effects on vocabulary acquisition [Unpublished master's thesis]. University of Surrey. Retrieved June 3, 2003, from http://www.surrey.ac.uk/ALRG/ dissertations/pdf/Sutton_J_1999.pdf

Tabatabaei, O., \& Shams, N. (2011). The effect of multimedia glosses on online computerized L2 text comprehension and vocabulary learning of Iranian EFL learners. Journal of Language Teaching and Research, 2(3), 714-725.

Tseng, S. S., Yeh, H. C., \& Yang, S. H. (2015). Promoting different reading comprehension levels through online annotations. Computer Assisted Language Learning, 28(1), 41-57. https://doi.org/10.1080/09588221.2014.927 366

Türk, E., \& Erçetin, G. (2014). Effects of interactive versus simultaneous display of multimedia glosses on L2 reading comprehension and incidental vocabulary learning. Computer Assisted Language Learning, 27(1), 1-26.
Warschauer Paribakht, T. S., \& Wesche, M. (1997). Vocabulary enhancement activities and reading for meaning in second language vocabulary acquisition. In J. Coady \& T. Huckin (Eds.), Second language vocabulary acquisition (pp. 174-202). Cambridge: Cambridge University Press.

Watanabe, Y. (1997). Effects of single and multiple-choice glosses on incidental vocabulary learning. JACET Bulletin, 28, 177-191.

Weijters, B., Cabooter, E., \& Schillewaert, N. (2010). The effect of rating scale format on response styles: The number of response categories and response category labels. International Journal of Research Market-ing, 27(3), 236-247. https://doi. org/10.1016/j.ijresmar.2010.02.004

Yanguas, I. (2009). Multimedia glosses and their effect on L2 text comprehension and vocabulary learning. Language Learning \& Technology, 13(2), 48-67. http://dx.doi. org/10125/44180

Yoshii, M., \& Flaitz, J. (2002). Second language incidental vocabulary retention: The effect of text and picture annotation types [Electronic version]. CALICO Journal, 20(1), 33-58. 